\title{
THE IMPORTANCE OF ORAL LANGUAGE PROFICIENCY IN EFL ONLINE TEACHING SETTING
}

Flora AMITI, PhD. C.

South East European University, Faculty of Languages, Cultures and Communication, English Department, amitiflora@ gmail.com

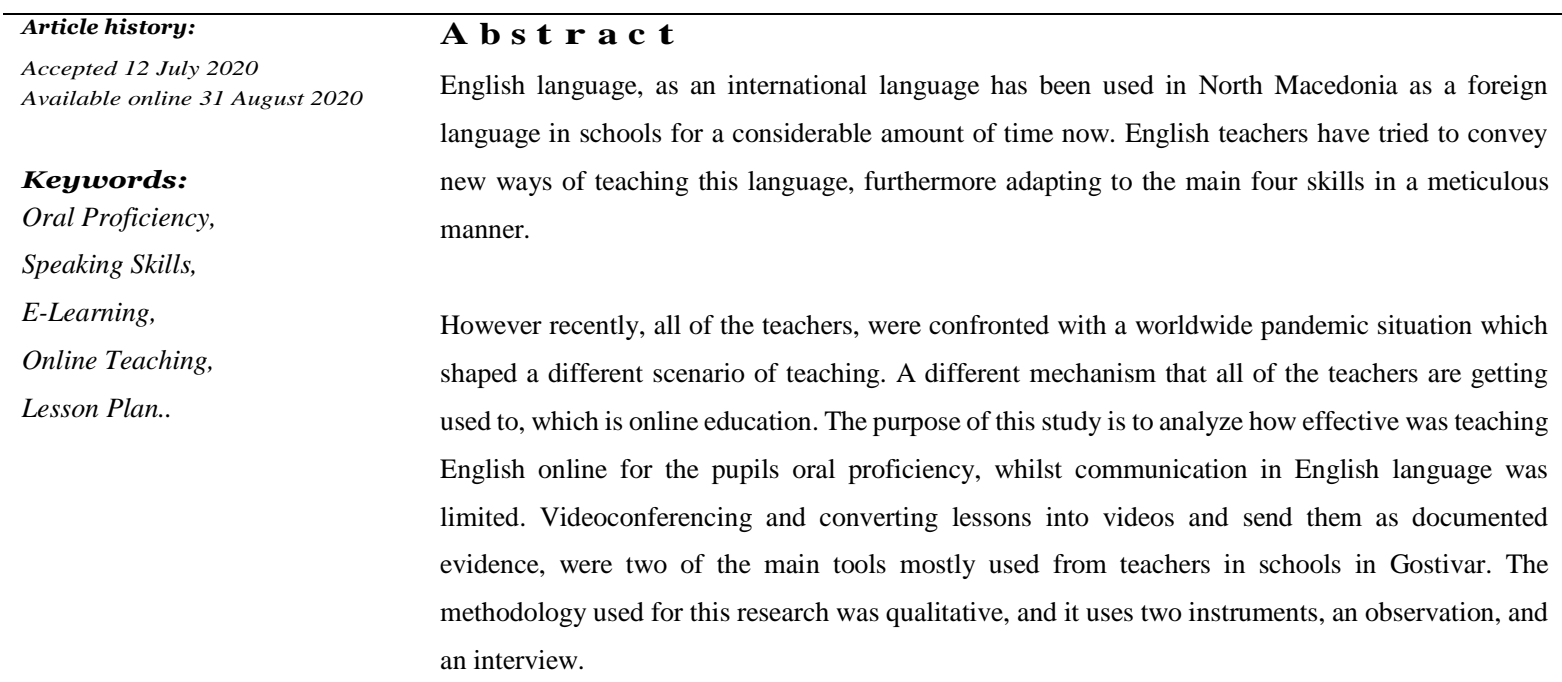

The overall study results show that, even though pupils showed improvement in EFL (English as a foreign language) oral proficiency, since the materials used to lecture online where persuasive; some students also had difficulties learning autonomously, without depending on the teachers help. Furthermore, according to the interview responses, the appropriate and detailed lesson planning, helps in combining activities which would emphasize speaking more in online teaching classes.

\section{Introduction}

Depending on the student's background knowledge, some students in EFLclasses are better in speaking English language. In other words, speaking, writing, listening and reading are the four skills which used correctly in combination by students, make a fluent conversation in English language. The teachers in the online classrooms should work hard to teach the four skills appropriately, but also apply different teaching methods which could help in improving student's oral proficiency.

According to Vilar (2000):

Teachers have two major roles in the classroom: to create the conditions under which learning can take place: the social side of teaching; to impart, by a variety of means, knowledge to their learners: the task-oriented side of teaching. The first is known as the 'enabling' or managerial function, the search for the proper conditions and means for teaching, and the second the instructional function with the teacher as the so-called “instructor”. (p. 4)

However, since all of the teachers in Gostivar, were only and exclusively prepared to teach in classrooms confronted by students, hence the traditional method of teaching in the classroom, it was a real struggle to begin with the online teaching method which interrupted the face to face encounters with the students. As noted by Barrera et al (n.d.):

Instead of following traditional paradigms that have the instructor firmly in control, we should adopt entrepreneurial and innovative approaches to learning. Such approaches would 
permit students to become independent learners, and, at the same time, give the teacher the important role of guide throughout the learning process. (p.7)

Moreover, the communication in English language continued in the online teaching tool named Google Classroom. The face to face communication had dropped unexpectedly, since the methods used were mostly by sending different materials, such as: Power Point Presentations, a summarized daily lesson converted into videos, or videoconferencing. However, the students were asked to send videos while speaking in English language, performing different oral activities. In addition, one of the most used tools for teaching online classes has been Google Classroom. As Shaharanee, Jamil and Rodzi (2016) mentioned "Google classroom can help in changing the focus of the classroom from one that is teacher-centered and controlled to one that is learner-centered and open to inquiry, dialogue, and creative thinking on the part of learners as active participants". (p.2)

Finally, since the speaking skill is the most important one which needs to be mastered, according to Bouzar (2019) "speaking as a skill constitutes a real hurdle to overcome by the teacher and the learner, the teacher has to find appropriate procedures to help the learner with, while the latter has to find a way to master the language”. (p.70)

Primarily, students need awareness on the significance of learning an international language, in this case, the teachers should state the importance of speaking English as a foreign language, its advantage for their future education in Gostivar and abroad but also encourage them to find ways to be in touch with each other in this period of pandemic, and communicate outside the class session too.

\subsection{Leson Planing}

According to Anderson (2015) "The lesson plan pro forma plays a central role in teacher education. It is a necessary component for the assessment of teaching during initial training, advanced qualifications, quality assurance inspections, and in-service teacher development." (p.228) In a lesson plan a teacher transcribes the aims and objectives of the lesson, methods of teaching, teaching techniques, evaluation methods etc., afterwards explains the class session approach in three parts:

1. Introduction

2. Activities

3. Summary and evaluation of the lesson effectiveness
The online classes, undergo the same procedure. Whilst the fact that videoconferencing is important to present the lesson to the students, importance should be given to all of the skills, but mostly 'speaking' since the amount of time they will incorporate speaking English in their everyday life is lower. The speaking activities should be incorporated a lot, at their spare time e.g. students are sent a song, and they should record a video while they sing it, students read a text in the book and record themselves while reading it, the teacher poses questions and expects students to reply by recording themselves while answering them.

Accoording to Albrahim (2020) online instructors must pay attention to what they need to create, develop, and manage their online courses and how to effectively communicate with the learners in the absence of physical presence and interaction. (p.12) The needs of students should be taken into consideration, but also the teachers viewpoint on the level of students oral proficiency.

Figure 1. 9 Steps of Student Guided E-Learning (Taken by Schneider and Meirovich, 2020).

\section{Step Diagram - Student Guided E-learning}

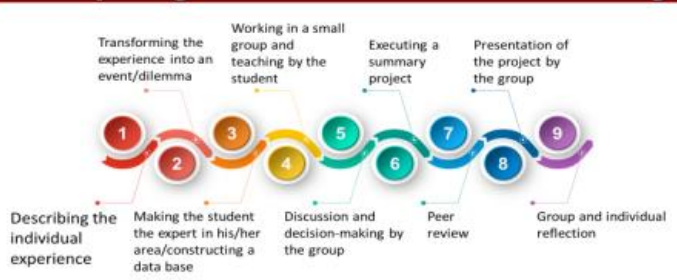

Online teaching is a real process, where it's shown that the online setting should be a student oriented teaching environment, in that way the student will be able to use the speaking skill the most. It should also incorporate group work, group reflection and decision-making in the group (see Figure 1).

An increasing amount of critical analysis and evidence have undermined that the "Online instructors must be able to do the following:

- Expressing and mastering extensive knowledge of the content; - Stating learning goals and objectives that coincide with learners' levels and characteristics;

- Drafting and developing learning and assessment activities that align with learning goals and objectives;

- Developing a course outline that includes all course components and elements;

- Designing a teaching proposal at the general level and identify each of its phases or elements; 
- Developing and selecting appropriate and varied learning resources that accommodate different learning styles and preferences;

- Linking the subject and content with scientific, social, cultural, and any other relevant phenomena; and

- Developing an inventory of existing content and resources and any additional content and resources that will be needed (Abdous, 2011; Bailie, 2011; Bailey \& Card, 2009; Bawane\& Spector, 2009; Munoz Carril et al., 2013)” (Albrahim, 2020).

\section{Literature Review}

Learning a new language brings its benefits in life, but it happens that some people are better at languages, some try harder to learn a new language, and others are motivated by external or internal factors. As mentioned by Marcum (2017) "Potential development is what a learner can do with the assistance of others. Actual development is what a learner can do on their own. Learning is the social process that helps a learner move through zones of proximal development, turning potential development into actual development".

Furthermore, it is important to stress the strategies used to learn a new language. If previously a student would depend on the teacher, in the traditional classroom setting; now it's the opposite. The students changed, as much as the way of teaching. The students gained their independence and try to use different strategies in learning. However, the speaking skill should be encouraged mostly by the teacher. As stated by Rao (2018):

The teacher should create interaction by exchanging information and expressing ideas with utmost care about the correct grammar (accuracy), adequate vocabulary, a good pronunciation as well as acceptable fluency to convey a meaningful speech that sounds like a native speakers' own by following the classroom activities such as role-pays, simulation, talking circles, discussions, debates, role cards, information gap activities, storytelling-based activities and so on. (p. 289)

Now more than ever the resourcefulness and the creativity of teachers is needed. Even though the teachers are not native speakers it's important to try to say the words correctly and try an accent too. It follows the idea of Prabavathi and Nagrasubamani (2018) who said that "There are many benefits of oral communication. This form of communication is a quick and direct method of communication. Be it a criticism or praise or information, it helps to convey the message immediately to the receiver. This method of communication enables in obtaining immediate feedback and hence is a form in which two-way communication can be enabled. (p. 30)
Moreover, even though students go into a transition process, where they are alone looking at a computer screen, and there is no teacher presence to explain the instruction or read the text, the students are obliged to find out how certain words are read, find the proper pronunciation on their own by using different pronunciation tools online. Definitely there should be a teacher's feedback as noted by Moore (1989) that the instructor is especially valuable in responding to the learners' application of new knowledge. Whatever self-directed learners can do alone for self-motivation and interaction with content presented, they are vulnerable at the point of application. (para. 8)

The oral proficiency is gained by repetition of words and sentences, so in an online setting if students have the recording of a text, and they hear it several times it benefits them. According to Moore (1989):

While the students and their instructor are attending to a common piece of presentation (usually in a set text, but quite likely on audio- or videotape), each student's response to the presentation is different, and so the response to each student is different. To some a misunderstanding is explained, to others elaborations are given, to others simplifications; for one analogies are drawn, for another supplementary readings suggested. (para. 7)

\section{Research Methodology}

The present study investigates the importance of speaking English on an e-learning environment and its benefits. The particular research techniques used are asynchronous observation and an interview.

\subsection{Research Question}

1. Does online teaching help in EFL oral proficiency improvement?

2. Is using the appropriate lesson plans helpful in e-learning classes?

\subsection{Instruments}

Two instruments were used for this study, an interview to the teachers which helped in regards to understanding the benefits of oral proficiency in EFL online teaching classes. It was important to recognize if the students were capable of making a progress in speaking the English language, even with inferior communication than the period there was tradition EFL teaching in the classroom. The second instrument was an asynchronous observation, in two different classes with 19 students in the fourth grade. During this research method the students were observed for a month. The communication in English language was taken into consideration while in videoconference, but also there was documented student participation also written feedback from the teacher. Hence, they 
were also given the opportunity to prepare videos individually e.g. songs, reading texts, prepare role plays etc. Thus speaking in English could be incorporated. Furthermore the students had time to answer whenever they were free to, there wasn't an attendance time limit.

\subsection{Participants}

The participants of the study were three English teachers from the primary school 'Faik Konica" in Debresh, Gostivar. Furthermore, 19 students from the same school were observed, they were in fourth grade and it should be taken in consideration that they have been learning English as a foreign language since 1st grade. They were between the ages 10-11, 14 female students and 5 male students.

\subsection{Research Results}

\subsubsection{Results from the Interview}

The first method used for this study was the interview. Three teachers tried to bring a closer look to the importance of speaking in an online teaching environment. There were 10 questions in this interview and the interviews were performed individually.

\section{$\mathrm{R}=$ Researcher}

$\mathrm{P}=$ Participant

Q1: What effect does online learning have on students?

P1: Online learning for students was difficult in the beginning since they weren't used to learning with computers in front of them, the technology part was difficult in the beginning too.

P2: Online learning has received much attention lately, for some students it was difficult since they didn't have the discipline to learn without a teacher as an authority.

Q3: Which one, of the four skills (speaking, writing, reading, and listening) was mostly used by the students while teaching online? P1: All of them.

P3: I believe reading, since the materials we sent them had a lot of instructions.

Q4: How difficult was it incorporating speaking skill during the online classes?

P1: It was difficult. Videoconferencing was thought to be the only way to communicate live, but since the time was limited we teachers needed the time to mostly lecture the new lesson.

P2: Speaking skill was mostly incorporated when the student had revision, so it was difficult to find ways to incorporate speaking the most.

Q7: Do you think students improved their oral proficiency while learning online?

P1: Depends on the student and the circumstances.
P2: The students had an interesting period of learning online, and I believe since we sent them different videos, songs etc. the repetitive listening of the language helped them in learning to combine words in the correct order, also speaking it properly.

P3: Some students really liked this kind of learning, so I believe it helped most of them.

Q8: What changes can be made in the lesson plan in order to stimulate students to use speaking more during the online teaching class sessions?

P1: We could add more discussions, simulations, storytelling and interviews.

P2: It should be a student oriented classroom, where we could send the lecture beforehand and afterwards they would explain it to use on a videoconferencing tool.

P3: The lesson plans guide teachers into having better classes, more interactive and interesting. Hence, preparing the lesson effectively and including speaking activities is crucial.

\subsubsection{Results from the Observation}

The second method used for this study was the asynchronous observation. It was crucial to perceive the use of the speaking skill while having online classes, and how everything proceeded in a recent however modernized way of teaching. The students were motivated to send different materials where they would express themselves in English language. The interaction between the teacher and the student was great, the dialogues in videoconferencing were productive and essential for the student's oral proficiency. Some students were having difficulties communicating in English language, even though they were urged to do so. Although, the asynchronous way of online teaching did help student have the time to prepare at least for the video presentations provided, and they were asked to be livelier. The observation was done through the specific observation protocol (Appendix 2).

\section{Conclusions}

Using English language for communication is really important. In this paper, an attempt was made to emphasize the importance of EFL oral proficiency in schools in Gostivar. Since it is not known how long the pandemic will last, we can still believe that we might return to online teaching in September. In this case it is important to foresee the mistakes we could be making and make a difference in the future.

Additionally, based on the interview results we could see that the speaking skills were incorporated in the online teaching lessons, but there were several difficulties with students discipline, also it was the first time the students were facing online classes. Furthermore, it was agreed that there should be incorporated more speaking activities and make a students oriented online classes. 
Finally, the observation showed that when students received the appropriate materials, e.g. a recording of a text, and were asked to memorize it and record themselves while saying the words; the students had difficulties in pronouncing some words, some couldn't connect the words and make a correct sentence. However, there were students who were motivated by the online teaching method, and had the urge to express themselves in English language as much as possible. The autonomous learning experience helped them give great results.

All things considered, as communication skills have an enormous importance in personal and professional lives, the students should be stimulated to speak and to express themselves. This research was solely done with the intent to influence and encourage teachers to help their students communicate, express themselves orally when having online teaching classes. The aim is to always think of the student's growth.

\section{References}

1. Albrahim, F. (2020). Online Teaching Skills and Competencies. The Turkish Online Journal of Educational Technology, 19(1), 9-20. Retrieved July 28, 2020, from https://files.eric.ed.gov/fulltext/EJ1239983.pdf

2. Anderson, J. (2015, July). Affordance, learning opportunities, and the lesson plan pro forma. ELT Journal, 69(3), 228-238. Retrieved July 29, 2020, from https://academic.oup.com/eltj/article/69/3/228/464325

3. Barrera, A., Ho, C., Garcia, I., Traphagan, T., \& Chang, Y.-F. (n.d.). Online vs. Face-to-Face Learning. Retrieved June 31, 2020, from https://www.academia.edu/1576750/Online vs Face to F ace Learning

4. Bouzar, S. (2019). Issues in Teaching Speaking to EFL Learners. Education and Linguistics Research, 5(23771356), 70-79. Retrieved August 01, 2020, from https://doi.org/10.5296/elr.v5i1.14705

5. Marcum , J. (2017). Language Proficiency and Cultural Intelligence in Distance. All Graduate Theses and Dissertations. Retrieved August 2, 2020, from https://digitalcommons.usu.edu/cgi/viewcontent.cgi?article $=7897 \&$ context $=$ etd

6. Moore , M. (1989). Editorial: Three Types of Interaction. American Journal of Distance Education, 3(2), 1-7. Retrieved July 30, 2020, from https://www.researchgate.net/publication/237404371 Thre

\section{e Types of Interaction}

7. Prabavathi, R., \& Nagasubramani, P. (2018). Effective oral and written communication. Journal of Applied and Advanced Research, S29 - S32.
8. Rao, P. S. (2018). Developing Speaking Skills in Esl or Efl Settings. International Journal of English Language, Literature, 5(2), 286-293. Retrieved June 15, 2020, from https://www.researchgate.net/publication/331825661_Dev eloping_Speaking_Skills_in_Esl_or_Efl_Settings

9. Schneider, L. N., \& Meirovich, A. (2020). Student Guided Learning - from Teaching to E - learning. Revista Românească pentru Educaţie Multidimensională, 12(1), 115-121. Retrieved June 18, 2020, from https://doi.org/10.18662/rrem/12.1sup2/254

10. Shaharanee, I. N., Jamil, J. M., \& Rodzi, S. S. (2016, August). Google Classroom as a Tool for Active Learning. Proceedings of the International Conference on Applied Science and Technology. Retrieved June 5, 2020, from https://aip.scitation.org/doi/abs/10.1063/1.4960909

11. Vilar, E. B. (2000). Roles of teachers - A case study based on: Diary of a language teacher (JOACHIM APPEL 1995). Retrieved July 25, 2020, from https://core.ac.uk/reader/61427370

\section{Appendix 1 - Interview}

1. What effect does online learning have on students?

2. What benefits are obtained of online teaching for you as a teacher?

3. Which one, of the four skills (speaking, writing, reading, and listening) was mostly used by the students while teaching online?

4. How difficult was it incorporating speaking skill during the online classes?

5. Was it difficult to manage time while teaching online and why?

6. Which tool should be used more, videoconferencing or converting the lecture into a video, in order to enrich the student's oral proficiency and why?

7. Do you think students improved their oral proficiency while learning online?

8. What changes can be made in the lesson plan in order to stimulate students to use speaking more during the online teaching class sessions?

9. Can learning online benefit the students in the future and how?

10. What kind of activities do you suggest should be used in online classes, in order to implement the speaking skill more? 


\section{Appendix 2 - Online Class Observation}

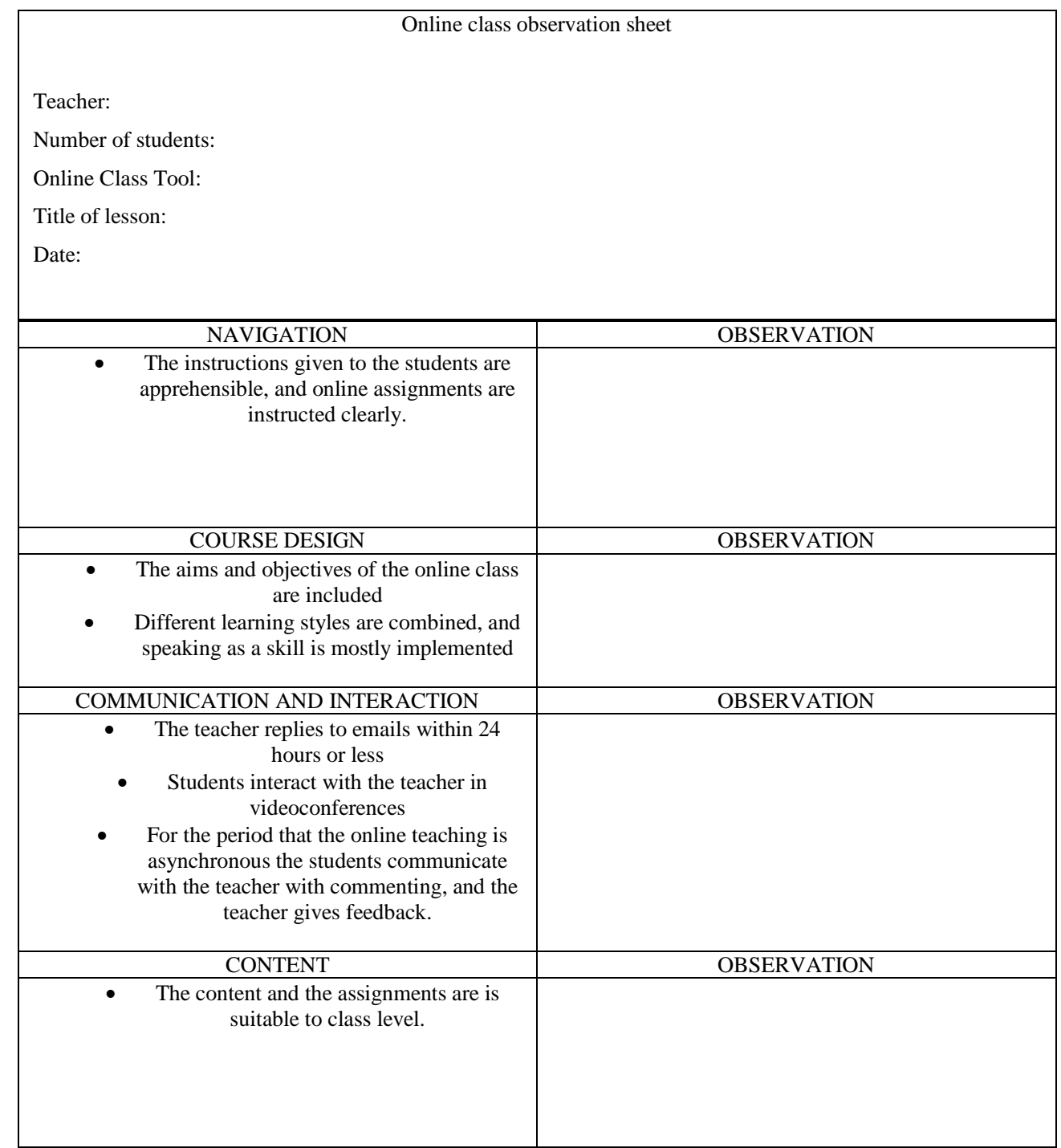

